\title{
Desafíos de la construcción de servicios civiles en Brasil y Uruguay
}

\author{
Conrado Ramos Larraburu \\ Universidad de la República, Uruguay \\ Alejandro Milanesi \\ Universidad de la República, Uruguay \\ Mauro Casa \\ Universidad de la República, Uruguay
}

La profesionalización de los servicios civiles resulta un aspecto fundamental para favorecer el desarrollo económico, social y la lucha contra la corrupción. En ese marco, los países del continente han realizado dispares esfuerzos por modernizar el empleo público, en muchos casos, obteniendo magros logros en términos de sostenibilidad e implantación efectivas. Dentro de un panorama diverso, Brasil y Uruguay se encuentran en un estadio superior de desarrollo de sus servicios civiles respecto de buena parte de los países de América Latina. Sus desafíos no pasan tanto por la construcción de las bases burocráticas mínimas, sino de un servicio público más profesional, orientado a resultados, capaz de ser un agente transformador de los procesos de desarrollo. En este artículo se centra en dos aspectos que a nuestro juicio tienen una capacidad transformadora central: la construcción de una Alta gerencia y la conformación de sistemas de carreras modernos.

Palabras clave: servicio público civil, gestión pública, desarrollo profesional, servidor público, burocracia, desarrollo social, análisis comparativo, Brasil, Uruguay

[Artigo recebido em 25 de maio de 2018. Aprovado em 28 de agosto de 2018.] 


\section{Desafios na construção de serviços públicos no Brasil e no Uruguai}

A profissionalização dos serviços públicos é um aspecto fundamental para promover o desenvolvimento econômico, social e o combate à corrupção. Nesse contexto, os países do continente fizeram esforços desiguais para modernizar o emprego público, em muitos casos, obtendo escassas conquistas em termos de sustentabilidade e implementação efetiva. Dentro de um panorama diverso, o Brasil e o Uruguai estão num estágio mais elevado de desenvolvimento de seus serviços públicos em relação a boa parte dos países da América Latina. Seus desafios não são tanto a construção de bases burocráticas mínimas, mas um serviço público mais profissional, orientado a resultados, capaz de ser agente transformador dos processos de desenvolvimento. Este artigo enfoca dois aspectos que, em nossa opinião, têm uma capacidade central de transformação: a construção de uma Alta administração e a formação de sistemas de carreira modernos.

Palavras-chave: serviço público civil, gestão pública, desenvolvimento profissional, servidor público, burocracia, desenvolvimento social, análise comparativa, Brasil, Uruguai

\section{Challenges in the construction of civil services in Brazil and Uruguay}

The professionalization of civil services is a fundamental aspect to promote economic and social development and fighting against corruption. Latin American countries have made disparate efforts to modernize public employment, in many cases, obtaining meager achievements in terms of sustainability and effective implementation. Within this diverse panorama, Brazil and Uruguay are in a higher stage of development of their civil services with respect to a good part of the countries of Latin America. Its challenges are not so much the construction of the minimum bureaucratic bases, but of a more professional public service, oriented to results, capable of being a transforming agent of the development processes. This article focuses on two aspects that in our opinion have a central transforming capacity: the construction of a top manager layer and the formation of modern career systems.

Keywords: civil service, public management, professional development, public servant, bureaucracy, social development, comparative analysis, Brazil, Uruguay 


\section{Introducción}

En las últimas décadas se ha popularizado un diagnóstico en América Latina que señala la necesidad de fortalecer las instituciones públicas para favorecer el desarrollo económico, social y la lucha contra la corrupción. En ese contexto, la profesionalización de los servicios civiles resulta un aspecto fundamental. Los países del continente han realizado con tal fin dispares esfuerzos por modernizar el empleo público. Las experiencias de reforma del Servicio Civil en la región han planteado la necesidad de reducir el peso fiscal de los gastos de personal, postulando el reemplazo de los "viejos sistemas de carrera" por esquemas más flexibles y orientados a resultados de gestión, obteniendo magros logros en términos de sostenibilidad en el tiempo e implantación efectiva.

Las dificultades para el desarrollo de reformas del servicio civil en la región son múltiples. Gaetani y Heredia (2002) destacan los de carácter políticoinstitucional, vinculados a la discrecionalidad irresponsable en los procesos de selección, promoción, cese y retribuciones y la colusión entre las élites políticas y administrativas. En la misma línea, Longo (2008) insta a hacer foco en la gestión del cambio organizativo y la economía política de la profesionalización del empleo público. Desde la ciencia política a nivel internacional (GRINDLE, 2010), e incluyendo el caso latinoamericano, se ponderan factores de resistencia de actores interesados en el mantenimiento del status quo, englobando a gobernantes, oposición política, partidos, órganos de control, empleados públicos en sus diversos colectivos, directivos y mandos medios estatales. En el mismo sentido, deben mencionarse las trabas derivadas del diseño institucional del sistema político, entre los que destacan el número de puntos de veto, la inestabilidad política, los déficits de liderazgo y el carácter secundario de estas reformas en la agenda gubernamental. Asimismo, parte de las resistencias responden a la cultura de los grupos sociales que configuran sus patrones de conducta colectiva, y a las carencias de capacidad interna para gestionar sistemas de empleo público profesional. La presión para el cambio, la construcción de coaliciones significativas y el discurso reformador coherente son variables clave para su éxito (LONGO, 2008).

Más recientemente, en la evaluación del Banco Interamericano de Desarrollo (BID) de 2014 se listan entre los desafíos de administración pública en América Latina reducir la dependencia excesiva en medidas de mérito ${ }^{1}$ e introducir mayor flexibilidad en la gestión de recursos humanos, reducir el énfasis en procedimientos

\footnotetext{
${ }^{1}$ Interpretamos este argumento como una crítica a la rigidez asociada a la estabilidad de los sistemas burocráticos tradicionales y no al sistema "de mérito", en el entendido que la flexibilidad no va en detrimento de los mecanismos meritocráticos.
} 
uniformes y centralizados, profesionalizar el segmento directivo, institucionalizar sistemas de gestión e información, implantar la gestión por competencias y del rendimiento, así como mejorar la compensación para motivar y retener al personal, fomentando explícitamente la captación y retención de talento joven.

Por último, debe enfatizarse que la politización de la administración pública sigue siendo un rasgo distintivo de los Estados latinoamericanos (PHILIP, 2003). La realidad regional, no obstante, es variada e incluye desde países que no poseen sistemas de servicio civil institucionalizados hasta otros con regímenes históricamente profesionalizados de servicio civil (LONGO; RAMIó, 2008).

Dentro de esta diversidad, Brasil y Uruguay se encuentran en un estadio superior de desarrollo de sus servicios civiles respecto de buena parte de los países del continente. Sus desafíos no pasan tanto por la construcción de las bases burocráticas mínimas, sino por edificar un servicio público más profesional, orientado a resultados, capaz de ser un agente transformador de los procesos de desarrollo.

En términos de autonomía y capacidad, las comparaciones regionales han colocado a Brasil como un país de burocracia meritocrática, compuesta por servidores públicos permanentes y con niveles especializados de conocimiento, incorporados a carreras profesionales mediante procesos de selección de estricta objetividad, con incentivos y capacidad para influir en procesos decisorios (CAVALCANTE; CARVALHo, 2015). Brasil es considerado uno de los países latinoamericanos con un servicio civil dotado de un mayor grado de profesionalización por su cumplimiento de los requisitos del modelo burocrático clásico (EVANS; RAUCH, 1999). Por su parte, de acuerdo a Filgueira, Heredia, Narbondo y Ramos (2002), el servicio civil uruguayo ha sido históricamente más amplio y profesionalizado que el promedio regional, siendo uno de los más antiguos, extendidos y consolidados. Los derechos y obligaciones de los funcionarios públicos están regulados en la Constitución de la República, la cual prescribe la independencia del servidor público del poder político y la inamovilidad de los funcionarios presupuestados (ITURBURU, 2014).

En términos de déficits generales de estos servicios civiles, autores como Pacheco (2008) han afirmado que el modelo meritocrático brasileño es incompleto y ha convivido siempre con formas politizadas de ingreso y permanencia del personal público al Estado, así como con presiones corporativas del funcionariado distorsivas de los sistemas de remuneración y beneficios. Asimismo, sostiene que el servicio civil adolece de excesivos privilegios, gran centralización y uniformización en las decisiones sobre recursos humanos, y reglas de promoción mayormente basadas en la antigüedad. En el caso uruguayo, si bien el servicio civil se caracteriza por una carrera funcionarial de larga data, la misma está signada por una importante 
distancia entre la normativa vigente y la realidad empírica, dada la multiplicidad de reglas ad hoc que formalizan prácticas ajenas a un servicio civil de carrera, dando lugar a una "meritocracia heterogénea" a partir de regulaciones superpuestas (FILGUEIRA et al., 2002). La carrera administrativa se ve vaciada de realidad operativa por las diversas formas de carrera informal y paralela, y por la discrecionalidad de los jerarcas políticos para definir retribuciones y ascensos por fuera de la misma.

Este articulo no pretende dar una respuesta comprehensiva a cada una de estas cuestiones relativas a las necesidades de reforma de los servicios civiles de ambos países, sino centrarse en dos aspectos que a nuestro juicio tienen una capacidad transformadora central: la construcción de una Alta gerencia y la conformación de carreras. En el primer caso porque la constitución de un cuerpo de funcionarios en los niveles superiores de la administración con alto grado de profesionalización es un elemento central para la conducción estatal. Es allí donde se expresa con más claridad las tensiones entre los subsistemas políticos y administrativos y donde residen buena parte de la capacidad de la burocracia para generar innovaciones. El segundo porque las lógicas que estructuran los sistemas de carreras son fundamentales para el desarrollo de las capacidades y los incentivos para el rendimientos y respuesta a las necesidades funcionales de la maquinaria político-administrativa.

El artículo se estructura de la siguiente manera. En primer lugar, se realiza una presentación del desarrollo histórico de los servicios civiles en Brasil y Uruguay con el objetivo de analizar su construcción, fortalezas y déficits históricos. A continuación, se realiza un breve estado de situación de los principales desafíos actuales del servicio civil en ambos países. Seguidamente, se abordan las discusiones respecto de los desafíos específicos de la construcción de una Alta Gerencia y un Sistema de carrera en Brasil y Uruguay. Por último, se delinean una serie de reflexiones y comentarios finales.

\section{Desarrollo de los sistemas de servicio civil brasileño y uruguayo.}

Las principales etapas e hitos para la configuración y desarrollo histórico de ambos servicios civiles pueden observarse en la Tabla 1: 
Tabla 1. Periodización del desarrollo histórico de los servicios civiles

Brasil Uruguay

\section{Periodo 1: La instauración del Estado Administrativo}

*1936: Pionero en establecer servicio civil de carrera, institucionalizado con el Consejo Federal del Servicio Público Civil, devenido en Departamento Administrativo del Servicio Público.

*Constitucionalización del sistema de mérito.
1943: Promulgación del primer Estatuto de Funcionario Público (segundo más antiguo en la región).

\section{Periodo 2: Avances en la "Administración para el desarrollo", crisis y autoritarismo}

*Constitución de 1952: estableció estatutos múltiples para distintos órganos estatales.

*1945-1964: Redemocratización y desarrollo económico; creación de la Comisión de Simplificación Burocrática, la Comisión de Estudios y Proyectos Administrativos y la Escuela Brasileña de Administración Pública.

*Constitución de 1946: reforzó la estabilidad y creó límites al ingreso por concurso, facilitando la "administración paralela" e "islas de excelencia" de burocracias profesionales.

*1964-1985: la Dictadura militar enfatizó la expansión de la administración indirecta. La Secretaría de Planeamiento asume un papel central, con el Programa Nacional de Desburocratización (1979). Fortalecimiento de planeamiento, coordinación e información, con órganos como el Instituto de Pesquisa Económica Aplicada. Creación de cargos de Dirección y Asesoramiento Superior (DAS) y Plan de Clasificación de Cargos (PCC).
*1954: Primeros diagnósticos sobre la Administración Pública.

*1957: Creación de Comisión Asesora sobre Administración Pública (CASAP).

1960: Creación de Escuela de Administración Pública.

*1964: Leyes presupuestales establecieron obligatoriedad del concurso para ingreso al Estado.

*Constitución de 1967 consagró la carrera de funcionarios presupuestados (inamovibles), así como los ingresos y ascensos por concurso. Creó la Oficina Nacional de Servicio Civil (ONSC).

*Incentivo del traslado de funcionarios públicos a la actividad privada y congelamiento de vacantes.

*1973-1985: la Dictadura militar destituyó 11.000 funcionarios y amplió la figura de contratado permanente. Intentos de "racionalización weberiana" en selección y ascenso de personal. 
Periodo 3: El servicio civil en la "doble transición" hacia la democracia y la reducción del Estado

*1985 (retorno democrático): Transformaciones "anti-centralistas", para reducir y agilizar la administración pública.

*Decreto-Ley № 2.299/86 para reorganizar, racionalizar y simplificar la administración, creando la Secretaría de Administración Pública.

*Creación de la Escuela Nacional de Administración Pública (ENAP) y carreras de Especialistas en Políticas Públicas y Gestión Gubernamental, para cargos superiores.

*Creación del Sistema Integrado de Administración de Recursos Humanos.

*Constitución de 1988: consagró estas reformas y estableció la competencia del legislativo para organizar la Administración; la equivalencia salarial entre funcionarios; un régimen jurídico único (RJU) para servidores; el derecho de sindicalización; y la ampliación de razones para pérdida de cargo por desempeño insatisfactorio del funcionario.

*1990: Con el gobierno iniciado en 1990, se promovió dimisión de funcionarios, y extinción o privatización de entes públicos. Intento de reforma para reducir costos: supresión de Secretaría de Reforma Administrativa, suspensión de estudios sobre carrera, debilitamiento de la ENAP, destrucción de sistemas de información, despido de funcionarios con contratos privados o inestables.
*1985 (retorno democrático): Restitución a funcionarios destituidos, se prohibieron nuevos ingresos y se promovieron políticas de capacitación. Se reinstala la ONSC y se habilita el ingreso a puestos técnicos mediante selección por concurso.

*Avance incremental en racionalización de la administración, desburocratización y gestión de empresas públicas.

* 1990: Con el gobierno iniciado en 1990, se apostó a la "modernización gerencial", modificando regímenes estatutarios en empresas públicas, e introducción de retiro voluntario en toda la Administración. Reducción de las plantillas por restricción a nombramiento de nuevos funcionarios (Ley 16.127/1990).

*Programa Nacional de Desburocratización (Decreto 500/91).

*Empresas públicas habilitadas a suscribir contratos con los gerentes, para dedicación full-time y cumplimiento de objetivos. 
Periodo 4: Reformas administrativas inspiradas en el paradigma del 'New Public Management'

*1995: reconstrucción del sistema de mérito y profesionalización en núcleo estratégico del Estado. Exámenes de entrada; fortalecimiento y ampliación de carreras; control de nómina; remoción de privilegios; sistemas de gestión y desempeño; e incentivos voluntarios para modificar perfil del funcionariado. Aplicación de gratificaciones por desempeño.

*1998: Enmienda Constitucional amplió el periodo de prueba de servidores; criterio de insuficiencia de desempeño; principio de eficiencia; desaparición de inamovilidad; habilitación de diversos regímenes laborales públicos.
*1995: se aceleró la reducción de personal, disminuyendo el peso de la Administración en el gasto público.

*1996: Reforma con el objetivo de acotar el tamaño y peso del Estado, flexibilizando y profesionalizando la función pública. Diseñada e implementada desde el Comité Ejecutivo para la Reforma del Estado (CEPRE), técnicamente potente y con alto respaldo político. Se modificó inamovilidad del funcionario, hacia un sistema de contratación a término, para estimular rendimiento con evaluaciones periódicas.

*2000-2004: Diseño del Sistema de Información de Retribuciones percibidas por los funcionarios y se realizó su análisis y simplificación. 
Brasil

Uruguay

Periodo 5: Fortalecimiento del servicio civil durante los gobiernos progresistas

*Contratación de funcionarios, especialmente para cargos de nivel superior, más allá de las carreras tradicionales, que fueron reestructuradas y dotadas de concursos para diversificar sus perfiles de ingreso. Creación de carreras de analista de infraestructura, analista de políticas sociales y especialista en regulación.

*Recomposición de burocracia mediante concursos, fortalecimiento de áreas tributaria y de control, policía administrativa y judicial.

*Régimen laboral único en el sector público, revocando por parte del Supremo Tribunal Federal la flexibilización de regímenes de 1998.

*2006: directriz salarial que vinculó remuneración variable a evaluación de desempeño.

*2008: monitoreo sistemático de actuación individual e institucional del Sistema de Personal Civil, que impactó en procesos de capacitación y desarrollo de carrera.

*Proceso continuo de mayor exigencia de formación como pre-requisito para ingreso, y concursos cada vez más competitivos; aumento de escolaridad y competencias de funcionarios mediante escuelas de gobierno.

*Aumento de servidores públicos efectivos en cargos de libre nominación, así como de mejor escolaridad y mayor *Eliminación de restricciones al ingreso de personal y regularización de contratos precarios. Ampliación de competencias de la ONSC para reclutamiento y selección.

* Creación de Sistema de Gestión Humana y reformulación de carrera.

* Impulso a la Escuela Nacional de Administración Pública y la capacitación.

*Negociación colectiva con servidores públicos y simplificación de conceptos retributivos.

*Evaluación atada a compromisos de gestión y aumento de concursos de oposición.

*2010: Reestructuras organizativas y de puestos de trabajo; registro de Vínculos con el Estado; posibilidad de cambiar funcionarios de escalafón; redefinición de funciones de alta prioridad y alta especialización; modificaciones en reglamentación de licencias; ascensos por concursos de oposición y méritos; reglamentación del ingreso a la Administración y creación de nuevas formas contractuales; y creación de la Red Uruguaya de Capacitación y Formación de Funcionarios del Estado.

*Portal Uruguay Concursa: ventanilla única para transparencia e ingreso meritocrático al Estado.

*2013: Nuevo Estatuto del Funcionario Público.

Fuente: Elaboración propia en base a: Cavalcante y Carvalho (2015); Enap (2015); Filgueira et al. (2002); Gaetani y Heredia (2002); Iturburu (2014); Nuesch (2014); Pacheco (2008); Ramos (2003); Reiner (1997); Sanguinetti (2013); Souza (2016). 
En el periodo 1 aquí definido, de instauración del Estado Administrativo, Brasil comenzó a adoptar consistentemente las reglas del modelo burocrático a partir de la década de 1930, con el concurso público como forma de acceso a los cargos, la estabilidad en el empleo, la pensión íntegra, la igual remuneración para atribuciones similares, y la organización de carreras como principio general de organización de la función pública. Ello implicó inaugurar un régimen estatutario, si bien incompleto (PACHECO, 2008), que daría lugar a una modernización y racionalización weberiana del Estado para el modelo económico del "Estado Novo" (CAvalCante; CARvalho, 2015). El Estado interventor requirió de una administración moderna y dinámica (REINER, 1997), la cual no impidió que se mantuvieran prácticas patrimonialistas (Escola NACIONAL DE AdMINISTRAÇÃo Pública, 2015), combinadas con islas burocráticas, calificadas y meritocráticas. Mientras tanto, en Uruguay, este periodo marca la configuración de un aparato estatal cargado de funciones y de funcionarios que lograría estar presente con "profundidad legal, social y económica" en la sociedad uruguaya, consolidando capacidades para proveer de forma regular bienes públicos a la mayoría de la población, y que combinaría importante clientelismo partidario con bolsones de profesionalismo y eficacia. Se instaló por lo tanto una administración pública sensible a las demandas sociales pero ajena a la racionalidad burocrática weberiana (FILGUEIRA et al. 2002).

El periodo 2 incluyó avances en la "Administración para el desarrollo", crisis y autoritarismo político en ambos países. En Brasil, inicia en 1945, con un periodo democrático de concentración de poderes y recursos en el nivel federal y descentralización en el nivel administrativo, que provocó el fortalecimiento de una tecnoburocracia altamente calificada (REINER, 1997). Ya en dictadura militar desde 1964, la racionalidad administrativa y la planificación se consolidaron, a partir de una alianza político-estratégica entre la alta tecnoburocracia civil y militar y la clase empresarial brasileña (Enap, 2015). Fruto de esa alianza, se visualizó una suerte de "hipertrofia" estatal en los principales sectores de la economía. En Uruguay, los años 50' y 60' reflejaron un periodo de búsqueda infructuosa de soluciones técnicas e institucionales al decaimiento de la capacidad estatal para mantener el patrón de altos niveles de clientelismo partidario con eficacia gubernamental. El aumento del tamaño y costo de la burocracia, y la acumulación de presiones insostenibles en el contexto de la crisis política, económica y social, abonaron el tumultuoso clima previo al golpe de Estado de 1973 (FILgueIRA et al., 2002).

El periodo 3, de servicios civiles en la "doble transición" (LANZARO, 1998) hacia la democracia y la reducción del Estado, supuso para Brasil un debilitamiento de la competencia y eficacia gubernamental (GAETANI; HEREDIA, 2002), debido a reformas incompletas y asistemáticas, solo enfocadas en la reducción del gasto 
público. También en Uruguay, a principios de los años 90', se priorizó políticamente la reducción del Estado y la contención del gasto público, a partir de una agenda reformista crítica de la tradición burocrático-weberiana (RAMOS, 1993; 2003). Cabe mencionar asimismo las diferencias temporales en la introducción de medidas universalistas para el acceso al servicio público de ambos países, que Uruguay formuló legalmente en 1964 (si bien su aplicación efectiva sería muy escasa) y que Brasil consagró formalmente recién mediante la Constitución de 1988.

El periodo 4 es definido como de avance en reformas inspiradas en el paradigma del 'New Public Management', que se materializó en Brasil con el gobierno iniciado en 1995, a partir del Plan Director de Reforma del Aparato del Estado impulsado por Luiz Bresser-Pereira, Ministro de Administración y Reforma del Estado (MARE), que propuso una combinación de transformaciones gerenciales y meritocráticas de acuerdo a la naturaleza diferencial de distintas áreas de la administración. En Uruguay, la reforma también iniciada en 1995 postuló superar gradualmente déficits de productividad y desempeño del funcionariado público, a partir de medidas como la definición de nuevas estructuras organizativas; el análisis de las actividades de los funcionarios -definiéndolas como tareas sustantivas o no de cada oficina pública-; la racionalización de la estructura salarial; el sistema presupuestario de evaluación de resultados con enfoque al cliente y con impacto salarial; el retiro "involuntario" de funcionarios; y la creación de cargos de Alta Especialización (RAMOs, 2003). Esta reforma consiguió que la Administración Pública uruguaya funcione con una modalidad más gerencial mas no solucionó los históricos déficits de informalidad y meritocracia heterogénea (FILgUeIRA et al. 2002).

En el periodo 5, signado por el advenimiento de Gobiernos progresistas en ambos países en la década del 2000', Brasil no experimentó una reforma explícita ni consolidada, sino que transitó diversas iniciativas incrementales para la gestión del personal, con el norte de una ampliación y revalorización de la burocracia federal y sus carreras, con énfasis en reconstruir el cuadro funcionarial y fortalecer la capacidad estatal en áreas consideradas estratégicas para el desarrollo, privilegiando las garantías a la estabilidad y la mejora salarial (PACHECO, 2008). Por su parte, los gobiernos progresistas de Uruguay implementaron una serie importante mas insuficiente de reformas, tendientes hacia un "neoweberianismo imperfecto", que avanza en la evaluación basada en el desempeño y en la flexibilización de las estructuras de carrera administrativa, pero sin lidiar efectivamente con los desafíos de fortalecer al servicio civil, de alcanzar la excelencia de las competencias profesionales, o de concretar una nueva cultura administrativa basada en la evaluación sistemática (RAMOS; MILANESI, 2016). 


\section{Estado actual de situación de los servicios civiles en Brasil y Uruguay}

Realizar un análisis comparado de los servicios civiles en Brasil y Uruguay no resulta una tarea sencilla en virtud de las importantes diferencias institucionales. El hecho de que Brasil sea un país federal y Uruguay unitario hace que muchas de las mismas funciones sean cumplidas en distintos niveles de gobierno. Uruguay cuenta con ministerios ejecutores de políticas, aunque con una tendencia a perder esas funciones por otras de diseño y regulación. En el caso de Brasil, la estructura federal hace que, salvo excepciones, la mayor parte de las políticas sean ejecutadas en los niveles estaduales en coordinación con el gobierno federal.

Las diferencias de tamaño de ambos servicios civiles dificultan comparaciones numéricas. El servicio civil federal brasilero es relativamente reducido. Los niveles estaduales y locales concentran buena parte de la ejecución de servicios. Aproximadamente el $12 \%$ de servicio civil se localiza en el sector federal, $36 \%$ de ellos como parte de las Fuerzas Armadas. En el caso de Uruguay, los vínculos de la administración central ascienden al $26 \%$ lo que da cuenta de estructuras organizativas diferentes. Sumado a ello, Brasil vivió un proceso de reformas gerenciales más profundo que el uruguayo, lo que hace que un conjunto de funciones sean ejecutadas por el sector privado. La cantidad de funcionarios públicos como porcentaje de la población ocupada es sensiblemente más alta en Uruguay que en Brasil.

\section{Tabla 2: Funcionarios públicos/población ocupada}

\begin{tabular}{ll}
\hline Uruguay & Brasil \\
\hline $18,4 \%(2016-$ ONSC) & $11,9 \%(2014-O C D E)$ \\
\hline
\end{tabular}

Por otra parte, la evolución del número de servidores públicos del Poder Ejecutivo (Federal en Brasil y Administración Central en Uruguay) presenta tendencias divergentes. Mientras que en el caso brasileño se constata un incremento sostenido desde el 2004, en Uruguay se da una tendencia inversa, aunque de menor magnitud, como consecuencia de la localización de servicios en estructuras externas al Poder Ejecutivo, en particular el sector salud. 
Gráfico 1: Evolución de servidores públicos activos del Poder Ejecutivo (Brasil 1988-2014)

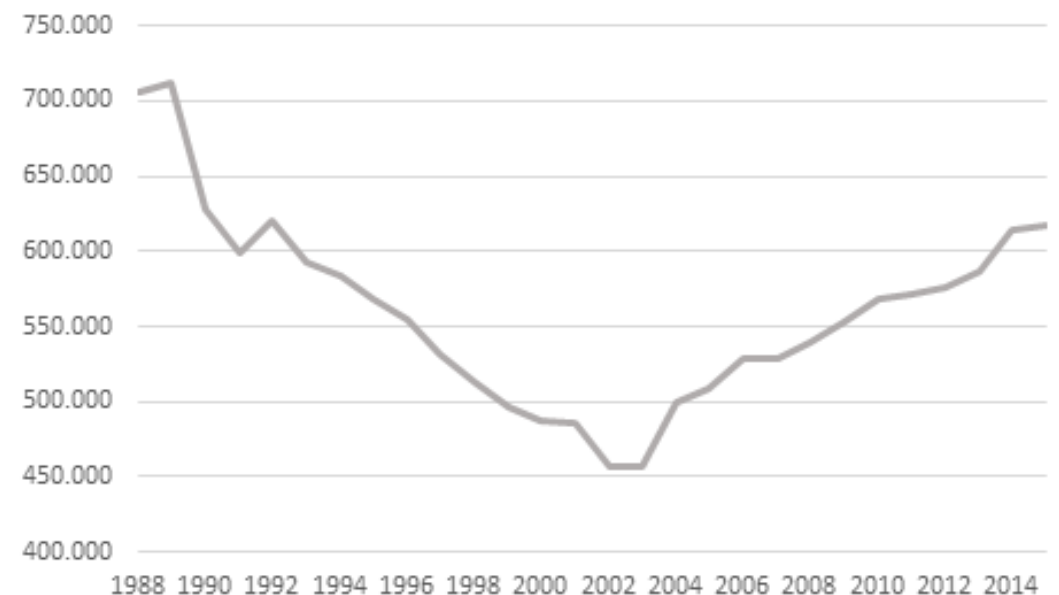

Fuente: Boletim Estatístico de Pessoal (SIAPE).

Gráfico 2: Vínculo de funcionarios del Poder Ejecutivo (Uruguay 1995-2016).

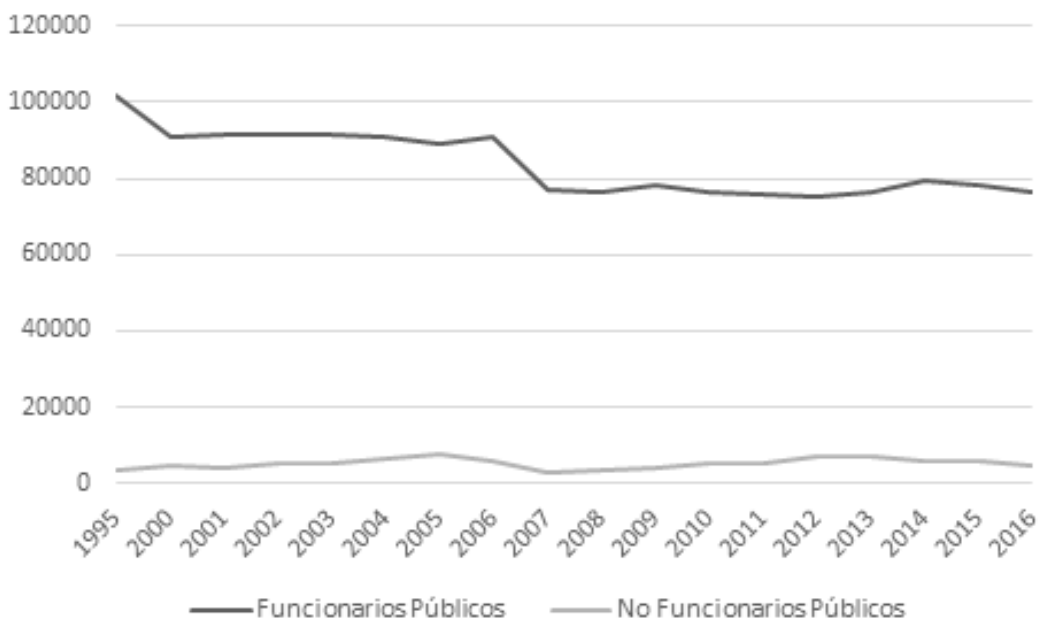

Fuente: ONSC (2016).

Este panorama heterogéneo torna más pertinentes las comparaciones en términos de calidad del servicio civil y desafíos, más allá de las estructuras institucionales o números macro disímiles. Para tal comparación, se hará uso de los indicadores del Marco Analítico para el Diagnóstico de los Sistemas de Servicio Civil desarrollado por el BID tomando los capítulos de Uruguay (ITURBURU, 2014) y Brasil (LLANO, 2014) y presentando algunos de los déficits identificados para cada caso nacional. 
Calidad y desafíos de los servicios civiles en Brasil y Uruguay

Desde esta perspectiva analítica, el Servicio Civil comprende el conjunto de arreglos institucionales mediante los que se articulan y gestionan el empleo público y las personas que lo integran. La calidad del sistema de gestión del empleo remite a la compatibilización de objetivos de eficacia y eficiencia con requerimientos de igualdad, mérito y neutralidad propios de administraciones profesionales en contextos democráticos, y dicho sistema es estudiado a partir de una serie de subsistemas (BID, 2002).

En términos del subsistema de planificación de recursos humanos, el informe del BID señala para Brasil una serie de déficits entre los que se destacan: la baja capacidad de las agencias para prever sus requerimientos de recursos humanos, la alta burocratización de los trámites para concursos y la rigidez para la redistribución de personal. Asociado a ello, las áreas de recursos humanos funcionan bajo un esquema procedimental típico de un modelo burocrático clásico que no cubre requerimientos gerenciales. Buena parte de estas rigideces ha tenido como consecuencia, al igual que en Uruguay, la ampliación de figuras de contratación más flexibles o transitorias. En este marco, algunos avances se han localizado en el intento por profesionalizar cargos técnicos de nivel superior, particularmente asociados a los cargos de Dirección y Asesoramiento Superior (DAS).

Uruguay presenta problemas similares: el débil vínculo entre presupuestación y necesidades de recursos humanos, las dificultades para ejecutar políticas de excedente de personal y los dilatados e infructíferos procesos de reestructuras funcionariales. Por otra parte, un fenómeno extendido para la designación de cargos en las estructuras superiores de la carrera burocrática ha sido la figura de "encargaturas". Se trata de personas normalmente internas a la organización que, por confianza política o técnica, son designados en puestos que no se corresponden con su situación en la escala funcionarial. Ello limita la planificación de recursos humanos y su vínculo con metas y objetivos organizacionales integrados a la carrera.

En el plano del sistema de carrera, uno de los principales problemas identificados en Brasil es la inexistencia de un sistema unificado de clasificación de puestos como consecuencias de los sucesivos cambios realizados. Ello tiene como resultado una multiplicidad de modelos de organización de cargos a la interna de las agencias federales. Se ha señalado también la escasa definición de perfiles por competencias para la confección de cargos o selección de funcionarios.

Un aspecto importante para destacar en Brasil es la creación de carreras transversales vinculadas a políticas sectoriales. La progresión en la carrera se da dentro de una misma clase o el cambio a una clase inmediatamente superior. Cada carrera tiene diferentes criterios que incluyen desde antigüedad a desempeño, y 
exigencias de capacitación. No obstante, la antigüedad sigue siendo el factor de mayor peso. En 2008 se aprobó un Sistema de Desarrollo en la Carrera con el objetivo de uniformizar la progresión de los funcionarios y un mayor foco en el desempeño. Sin embargo, este sistema ha tenido fuertes resistencias para ser implementado. Las carreras son cortas, alcanzando su tope en un promedio de 12 a 13 años, lo que incrementa presiones salariales y reajustes a la carrera. A su vez, buena parte de las expectativas de movilidad de los funcionarios se cubren a través del acceso a los DAS u otras funciones comisionadas, pero sin mecanismos formales de ascenso.

En el caso de Uruguay, la organización del sistema de carrera limita las posibilidades de ascenso, como consecuencia de un engorroso proceso y la mencionada designación de encargaturas. La movilidad horizontal es prácticamente inexistente apelando en muchos casos a los denominados "pases en comisión" u otras figuras. Sumado a ello, en el caso uruguayo, un punto clave del sistema de carrera es su organización en base a estructura corporativas y no familias ocupacionales. La selección de candidatos se realiza de acuerdo a competencias profesionales más bien genéricas. A su vez, los concursos de ascenso deben realizarse de forma interna a la organización y sólo cuando el llamado es declarado desierto puede definirse un procedimiento abierto.

\section{Gráfico 3: Subsistemas del índice de Desarrollo del Servicio Civil - BID}

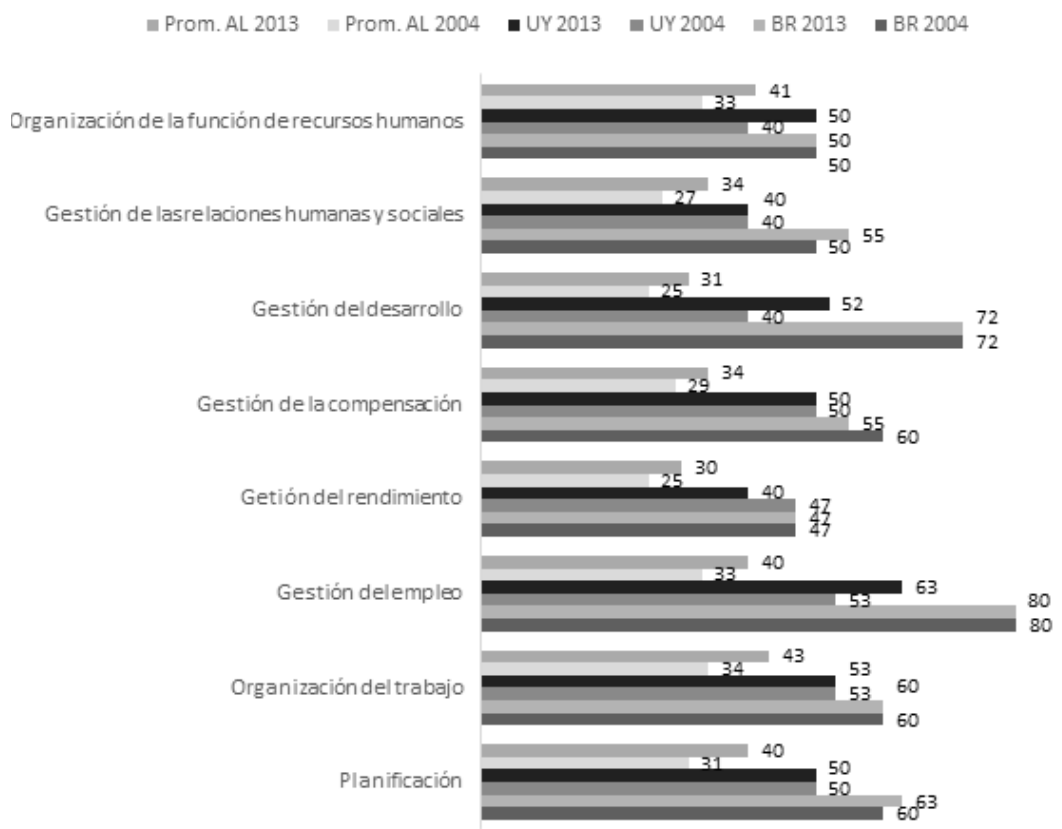

Fuente: BID (2014). 
La generalización de un sistema fiable de ingreso meritocrático en Brasil que impide (o limita) mecanismos informales o clientelares es un punto a destacar. La ejecución de los concursos es realizada por prestadores independientes mediante licitación pública. Como contracara, la interpretación restringida de los instrumentos de selección, prueba y títulos, limita la incorporación de otras herramientas útiles para analizar las habilidades y competencias de los candidatos en el reclutamiento. Al igual que en Uruguay, la movilidad horizontal en el servicio civil brasileño es escasa, particularmente para las carreras más antiguas. Los DAS y las funciones de confianza permiten mayor movilidad lateral, lo que en la práctica configura una competencia a la interna del sector público. En cuanto a la desvinculación, el sistema es altamente estable. Los funcionarios sólo pueden ser destituidos por faltas graves y el mal desempeño no opera como un factor de desvinculación en la práctica.

En el caso de Uruguay, en 2010 se creó Uruguay Concursa, dependiente de la ONSC para la gestión de los concursos pertenecientes a la administración central, siendo posteriormente ampliado a todas las entidades públicas. Para ello se elaboró un marco normativo específico y sistemas de información de soporte. A partir de entonces, todas las organizaciones publican los concursos disponibles y sus fases de selección, otorgando mayor conocimiento del proceso a la ciudadanía. El sistema favorece la automatización del proceso, pero también su control, limitando discrecionalidades. A su vez, permite generar información agregada que favorece el conocimiento y planificación global de los concursos de la administración. Un punto para destacar, es que Uruguay ha hecho importantes avances en el registro de los vínculos laborales, lo que genera transparencia y permite identificar mecanismos de ingreso según las organizaciones.

En cuanto a la evaluación, si bien Brasil avanzó en la creación de un sistema general de evaluación basado en metas institucionales e individuales, su grado de desarrollo es entre las agencias es disímil, tanto por factores culturales como de capacidades para su ejecución. Un punto clave en este esquema es el componente salarial ligado a desempeño, el cual representa entre el $50 \%$ y el $100 \%$ de salario base; prácticamente el único incentivo en funcionamiento. Este componente adicional ha promovido la fijación de metas simbólicas o accesibles, que lo asocian a lo punitivo más que a una herramienta de estímulo. Un punto crítico es además la falta de mecanismos formales de evaluación de los cargos gerenciales lo que limita el vínculo entre el rendimiento de los cargos a nivel estratégico, con los técnicos y administrativos.

En Uruguay, también existen fuertes carencias en términos de evaluación, con sucesivas adopciones y abandonos de políticas de retribución por desempeño. Asociado a ello, si bien se ha intentado generar un nuevo sistema de evaluación de 
funcionarios, su implementación puede ser señalada como una de las debilidades más relevantes en el sistema de gestión humana del sector público uruguayo. A su vez, los sistemas de retribución por desempeño existentes son aislados y presentan rasgos de ritualización y discrecionalidad importantes.

Un punto crítico del actual sistema de gestión del servicio civil en Brasil tiene que ver con los mecanismos de remuneraciones y compensación. Si bien los salarios públicos han mejorado, lo que genera mayores incentivos para que candidatos competitivos ingresen a la función pública y se ha avanzado en recortar las brechas salariales internas, persisten una serie de déficits: disparidades salariales entre poderes de gobierno y entre carreras del Poder Ejecutivo, lo que genera alta rotación y competencia entre agencias; múltiples escalas salariales entre carreras (diferencias entre $1 \%$ y $133 \%$ entre el piso y el techo); ausencia de un modelo de remuneración variable uniforme; incremento de los cargos sin remuneración variable; diferencias salariales entre cargos DAS ocupados por funcionarios y no funcionarios.

En el caso de Uruguay, el salario público tuvo un aumento importante (37\% entre 2004 y 2013). A su vez, se fortalecieron los sistemas de información que dan cuenta de la distribución salarial entre funcionarios lo que permite identificar las brechas salariales. No obstante, persiste la utilización de mecanismos de compensaciones variados a la interna de las organizaciones, lo que genera disparidades verticales y horizontales respecto de las mismas posiciones en distintos organismos. La mayor parte de las compensaciones está vinculada a los lugares específicos de trabajo, a conquistas corporativas o discrecionalidad de los jerarcas, lo cual agrega irracionalidad e inequidad al sistema.

Gráfico 4: Índices de Capacidades BID

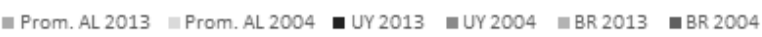

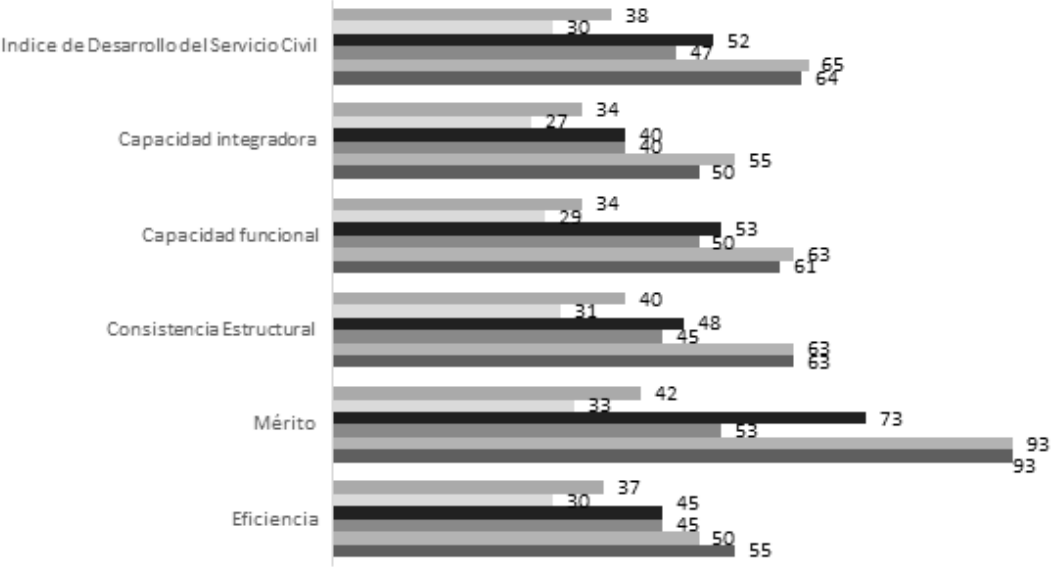

Fuente: BID (2014). 


\section{Sistemas de carrera y Alto Servicio Civil: dos arenas en disputa}

Con miras a complementar tanto la comparación histórica entre los periodos de desarrollo de los servicios civiles, como la caracterización de las dimensiones que conforman los sistemas de gestión de recursos humanos de ambos países, se seleccionaron para un análisis comparado en mayor profundidad, por su capacidad transformadora de los servicios civiles, los tópicos de estructuración de las carreras administrativas y de construcción del Alto Servicio Civil profesional, que se presentan a continuación.

\section{Los sistemas de carreras}

Las administraciones públicas latinoamericanas con desarrollos estatales más maduros, están formalmente estructuradas en sistemas de carrera, que han convivido históricamente con reglas informales. En ese sentido, es frecuente encontrar en un mismo organismo público sistemas de vínculos laborales ajenos a la carrera administrativa; estructurados como puestos de trabajo de designación directa por parte de las autoridades políticas (patronazgo), o mediante diversos contratos de trabajo ajenos a la planta estable de funcionarios. Si bien el sistema de carrera en la función pública garantiza la aplicación de los principios meritocráticos y la imparcialidad en los actos administrativos, no por ello es sinónimo de eficiencia en el diseño e implementación de las políticas públicas. En los sistemas de carrera donde los funcionarios pertenecen a un cuerpo especializado a partir de sus titulaciones, la ventaja de la especialización profesional conlleva asimismo el riesgo de desarrollar un espíritu de cuerpo con intereses corporativos. En cambio, los sistemas de empleo sacrifican la especialización a favor de la premisa que reza "el mejor funcionario para la tarea".

Así y todo, un sistema corporativo de carrera puede estar estructurado de forma más abierta, permitiendo ascensos horizontales dentro del mismo grupo, pero entre distintos organismos públicos, o más cerrada, favoreciendo la especialización funcional al interior de una misma área de gobierno (functional village). Es fundamental comprender cómo se estructuran los sistemas de carrera y cómo se definen los perfiles y cargos que los constituyen, con el objetivo de analizar su coherencia y rendimiento con respecto a las necesidades funcionales de la maquinaria político-administrativa.

Partiendo del caso brasileño y siguiendo a Dias (2010), las carreras administrativas en el Gobierno Federal están formalmente asociadas a la finalidad del organismo donde se desarrollan. Sin embargo, existe un importante número de instituciones donde sus carreras no están asociadas a su finalidad, sino al Plan General de Cargos 
del Poder Ejecutivo (PGPE). Este fenómeno responde a que la clasificación de algunos organismos como constitutivos de actividades "del núcleo duro" del Estado (no transferibles al sector privado), se hizo de manera incompleta. En consecuencia, muchos funcionarios que cumplen funciones de apoyo en órganos esenciales no son clasificados en la carrera correspondiente, ni acceden a sus beneficios asociados.

Muy distinta es la realidad que se evidencia de las trayectorias de carrera en Uruguay, cuyo nivel de desarrollo dista del observado para Brasil; país pionero en la región en estructurar sistemáticamente las carreras del sector público, más allá de los significativos desafíos que contemporáneamente enfrenta dicho armado. En primer término, debe señalarse que en Uruguay una importante proporción de funcionarios públicos no pueden ser definidos como "funcionarios de carrera", ya que junto a éstos han convivido durante décadas "funcionarios contratados permanentes". Los contratos de estos últimos son automáticamente renovados cada año, lo cual en la práctica los dota de estabilidad en el puesto. A su vez, pueden ascender a puestos de superior jerarquía por la vía de nuevos contratos, lo cual genera una carrera informal y paralela a la del funcionariado de carrera. La existencia efectiva de la carrera funcional legalmente prevista se ve también desvirtuada por el hecho de que los puestos de trabajo sean habitualmente asignados a funcionarios que no detentan el cargo correspondiente. Si bien la carrera administrativa no desaparece, se vacía así de realidad operativa en la forma de responsabilidades y tareas concretas.

Para el caso en que la carrera efectivamente existe, el sistema uruguayo es rígido y corporativo. En este, "se hace carrera" dentro de un Inciso o Unidad Ejecutora (UE), la misma se estructura en torno a profesiones y oficios tradicionales, y el ingreso ocurre en el grado más bajo de la escala del escalafón correspondiente (RAMOS, 2013). El personal público en el Gobierno Central ha estado tradicionalmente organizado en escalafones según sus funciones realizadas, título académico o forma de contratación. De acuerdo a Ramos (2013), el nuevo Estatuto del Funcionario Público (Ley 19.121 de 2013) introdujo el concepto de ocupaciones, que dota de cierta flexibilidad a la carrera funcional, aunque tales ocupaciones quedaron asimiladas a carreras universitarias, bloqueando la posibilidad de incorporar familias ocupacionales transversales en el sector público. Si bien la carrera continúa cerrada a ingresos laterales (de fuera de la administración pública y a niveles intermedios), se abre horizontalmente en los puestos de Administración Superior, cuando se hayan agotado las posibilidades de contratar a un funcionario público. No obstante, este formato no presenta apego alguno la finalidad de los organismos a los que se vinculan o a algún formato de planificación general de cargos como sucede en Brasil y las posibilidades de carrera continúan variando fuertemente según la pertenencia a escalafones y organismos. 
En términos de déficits, la carrera funcionarial en Uruguay evidencia una importante distancia entre la normativa vigente y la realidad empírica, que da lugar a una "meritocracia heterogénea" a partir de regulaciones superpuestas que normalizan prácticas que debieran ser excepcionales como pases en comisión, partidas salariales extra-presupuestales, y las múltiples inconsistencias señaladas entre puesto, función, escalafón y remuneración. El sistema de remuneración en Uruguay desincentiva que los funcionarios no profesionales desarrollen tareas complejas por las que no serán remunerados adecuadamente dado que la mayor proporción de su salario está determinada por la categoría en las que se los clasifica de acuerdo al nivel de sus estudios (RAMOS, 2013). Si bien algunas inconsistencias similares a las aquí descritas pueden también rastrearse para el caso brasileño, las razones que las producen son claramente distintas, dado el proceso de constitución de carreras que Brasil ha transitado durante décadas. Como señalan Graef y Barbosa (2008), este proceso que data de la clasificación de cargos de 1970 ha atravesado sucesivas -e inconexas- reformas, que generaron confusión entre modelos de organización de cargos conflictivos entre sí. Conviven así planes de carreras por áreas de actividad (Ciencia y Tecnología, Medio Ambiente, Seguridad Social); por órgano o basadas en autarquías (Agencias Reguladoras, BACEN, INCRA, Fundaciones); por actividades sectoriales específicas (Analista de Comercio Exterior, Auditor Fiscal de Trabajo); por actividades transversales (Analista de Infraestructura, Desarrollo de Políticas Sociales); y centralizadas en organismos, pero de ejercicio descentralizado (Planeamiento y Presupuesto, Finanzas y Control, Abogacía del Estado). Lo que es común a todas estas carreras es su naturaleza técnico-administrativa, alejada de las tareas gerenciales reservadas para los DAS, con excepción de la carrera de Políticas Públicas y Gestión Gubernamental, que sí las desempeña. En términos semejantes al sistema uruguayo de escalafones rígidos y determinados de acuerdo a lógicas corporativas, las condiciones profesionales disímiles que brindan los distintos tipos de carrera en el Gobierno Federal brasileño son consecuencia de la combinación de criterios corporativos y políticos que han primado por sobre una adecuada valoración técnico-profesional.

Más aun, estos distintos tipos de carrera que prevé el sistema brasileño conviven dentro de un mismo organismo, provocando oportunidades de desarrollo profesional y retribuciones dispares, tal como sucede en Uruguay, donde existen notorias asimetrías entre funcionarios derivadas de la complejidad y heterogeneidad del régimen salarial. La estructura salarial de un funcionario público uruguayo comprende una gran cantidad de partidas que varían según las Unidades Ejecutoras, Incisos o escalafón de pertenencia, así como del grado de la escala de cargos, lo cual genera inequidades entre funcionarios, tanto a nivel horizontal como vertical. Dicho fenómeno aumenta la discrecionalidad del jerarca de turno para retribuir de 
manera diferencial a los funcionarios y disminuye el interés de éstos por avanzar en la carrera administrativa formal. La falta de oportunidades de desarrollo en la carrera administrativa y un sistema de remuneraciones que no se corresponde con el desempeño y valor público que agrega el funcionario a la sociedad provocan déficits de motivación ampliamente diagnosticados (RAMOS, 2013; IACOVELLO; ROdRíGUEz GUSTA, 2006; GUINOVART, 2002; NARBONDO; RAMOS, 1999).

A modo de reflexión sobre el apartado, mientras que en Brasil existen problemas de convivencia entre las distintas lógicas de constitución del sistema de carreras (horizontales y verticales), que imponen fuertes desafios de articulación y gestión, en Uruguay las dificultades -más profundas- están determinadas por un sistema de carrera rígida en lo formal en el que aun predomina la tradicional lógica corporativa basada en acreditaciones, y permeado de informalismo en la práctica. Por ello, vale la afirmación de que las dificultades detectadas para el caso brasileño son indicativas de un grado superior de desarrollo del sistema de carrera en comparación con Uruguay.

\section{La constitución de un Alto Servicio Civil profesional}

La constitución de un cuerpo de funcionarios en los niveles superiores de la administración con alto grado de profesionalización es un elemento central para la governance de las sociedades modernas. Este nivel expresa las tensiones entre los subsistemas políticos y administrativos en las democracias modernas, derivados de la necesidad de compatibilizar simultáneamente los imperativos de neutral competence y political responsiveness. De allí, el alto servicio civil profesional debe resolver esta tensión operando con la lógica de responsive competence. De lo contrario, una irresponsive competence refleja un cuerpo burocrático con capacidad de bloquear la implementación de los objetivos del gobierno, o una responsive incompetence da cuenta de una institucionalidad burocrática tan permeada por la política que no asegura capacidades técnicas para procesar las políticas públicas.

Como consecuencia de las reformas inspiradas en el New Public Management, los altos servicios civiles en los países desarrollados han incorporado estilos gerenciales que modificaron estos pactos entre políticos y servidores públicos. Las competencias entonces requeridas son las de manager (no las del analista o generalista), las recompensas son más heterogéneas (pagos por desempeño) y menos asociadas a la estabilidad en el cargo, y las lealtades están más estrechamente vinculadas a la implementación eficiente de las políticas (y menos vinculadas al free and frank advice). La intencionalidad subyacente ha sido la de garantizar un mayor control político sobre el servicio civil y disminuir la excesiva autonomía de la burocracia (HOOD, 2000). 
En América Latina, han sido escasas las iniciativas de profesionalización de los altos ejecutivos, y la confianza política sigue siendo el criterio predominante para la provisión de cargos jerárquicos (CORTÁzAR; FUENZALIDA; LAFUENTE, 2016). La transición hacia una lógica gerencial, a nivel de los sistemas de Alta Dirección Pública no significaría un tránsito desde un sistema de mérito hacia uno de corte gerencial, sino desde uno basado en el patronazgo y la confianza política hacia uno predominantemente meritocrático-gerencial. Estas iniciativas apuntarían tanto a establecer barreras al avance de la política sobre la administración pública como a instalar capacidades directivas para expandir la profesionalización hacia las distintas esferas administrativas. Instalar la lógica del "mérito gerencial" implica transformaciones en las tres dimensiones del pacto tipo spoil system: las competencias ya no estarían asociadas a la pertenencia partidaria o confianza personal, las recompensas ya no están asociadas a retribuciones discrecionales o estabilidad ligada al apoyo del jerarca político, y la lealtad no dependería ya del perfil político del designado (RAMOS; SCROLLINI, 2013).

La creación de los DAS en Brasil estuvo inspirada en el Senior Executive Service (SES) del Gobierno de Australia, cuyo rol es dotar al servicio público de dicho país de un liderazgo estratégico altamente cualificado, que contribuya a la efectividad y cohesión del sector público. A diferencia del SES australiano el DAS no tiene un sistema de reclutamiento, promoción y evaluación del desempeño meritocrático, ni promociona expresamente las habilidades gerenciales ni siquiera cuando se trata de funcionarios provenientes de las distintas carreras. La única carrera que prepara para cumplir funciones gerenciales (y no técnico administrativas) es la de Especialista en Políticas Públicas y Gestión Gubernamental (EPG). El número de cargos DAS ha ido experimentando una reducción importante en los últimos tiempos. Como consecuencia de la Ley 13.346 de 2016, se eliminaron aproximadamente 10.000 de estos cargos. Los DAS fueron sustituidos por las Funciones Comisionadas del Poder Ejecutivo (FCPE), ocupadas exclusivamente por cargos de carrera. El Decreto № 9.021 de 2017 modificó los porcentajes mínimos de ocupación de los servidores públicos de los cargos DAS, en tanto los FCPE se destinan a la sustitución de parte de los cargos DAS de libre elección de 1 a 4 . Ello aceleró la reducción de cargos de designación directa que han caído en más del 50\% desde el 2014.

La mayoría de los análisis que se han hecho sobre los DAS apuntan a que no es un sistema con criterios de reclutamiento, selección, inducción, entrenamiento, evaluación del desempeño, y retención una vez fuera de la función., que refleje la madurez de un Sistema de Alta Dirección Pública, sino que mantiene un funcionamiento basado en la confianza política. La limitación de esa base de confianza reside en la proporción de cargos destinados a funcionarios de carrera que 
apunta a la predominancia de insiders en las altas esferas (60\% en niveles 5 y 6), y por partes iguales en los otros niveles (50\% en niveles 1,2,3 y 4). La confianza política como base del sistema, en lugar de las evaluaciones de desempeño, desincentiva a los funcionarios en la adopción de riesgos y en su capacidad de innovación. El apoyo político, que es la medida de éxito de su gestión, no depende necesariamente de su desempeño técnico. Por ejemplo, en la medida que sean funcionarios, los DAS de nivel 5 y 6 se diferencian del caso alemán en que allí una comisión revisa el mérito del perfil de dichos cargos de confianza. Brasil ha debatido si hay un proceso de politización del Estado vía aumento de los DAS de nivel 5 y 6, pero se aduce que en los gobiernos progresistas han crecido sustantivamente Ministerios y agencias, lo que conduce a un aumento proporcional de estos cargos.

\section{Gráfico 5: Evolución de los cargos DAS}

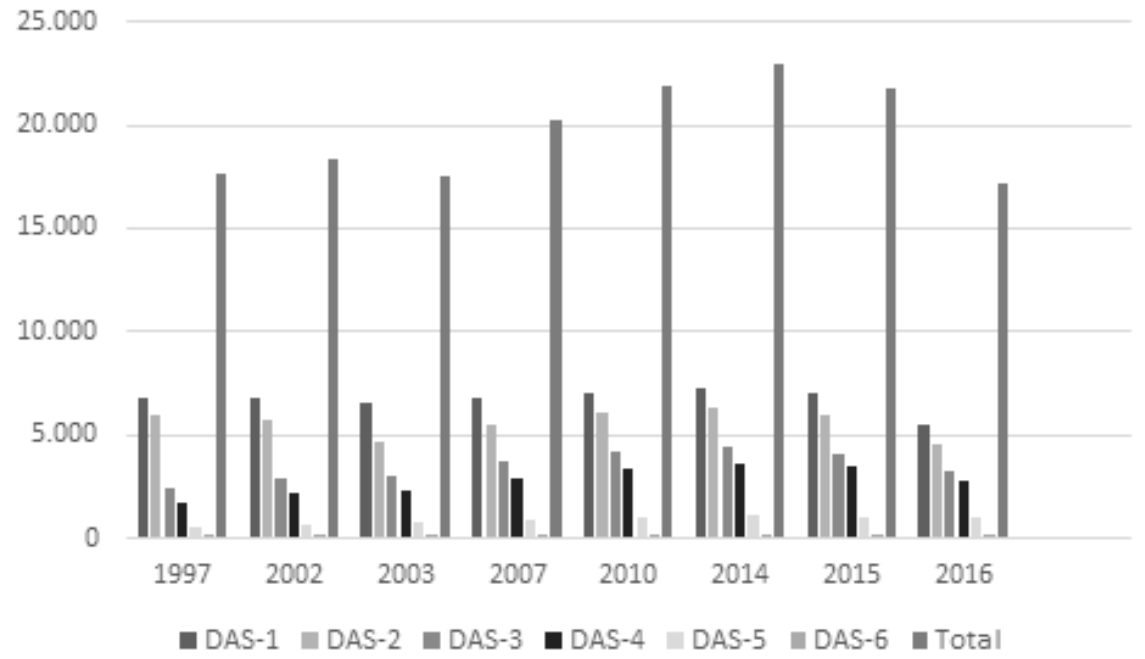

Fuente: Ministério do Planejamento, Desenvolvimento e Gestão.

Las lógicas detrás de estas designaciones, así como la porosidad de los distintos organismos a la politización de estos cargos también está siendo estudiada. Tales lógicas remiten no sólo al cumplimiento de la agenda presidencial, sino también a las necesidades del presidencialismo de coalición (GARcía, 2015). En cuanto a la porosidad, algunos estudios sostienen que los organismos de menor relevancia política son más proclives a usar DAS que no pertenecen al Servicio Civil, así como los Ministerios nuevos, sin carreras sólidamente estructurada, politizan más fuertemente. También hay diferencias entre la administración directa y la indirecta, esta última con carreras especializadas más cerradas a la presencia de 
outsiders mientras que las agencias centrales utilizan mayormente a los EPG, por sus competencias para coordinar políticas transversales.

A pesar de las limitaciones apuntadas en cuanto a la ausencia de un sistema desarrollado de evaluación del desempeño, los análisis de los niveles DAS conocidos como Burocracia de Medio Escalón (BME) (del nivel 1 al 5), demuestran que en términos generales es un cuerpo de profesionales muy capacitado. En su amplia mayoría, pertenecen al servicio civil de carrera, donde los criterios técnicos de selección predominan, y donde coordinadores y directores de proyectos desarrollan altas capacidades de articulación y negociación con stakeholders (CAVALCANTE; LOTTA, 2015). Persiste de todos modos la necesidad de establecer una mayor distinción entre funciones de gestión directiva y de asesoría, para lo cual los cargos DAS requieren perfiles distintos y deberían recibir capacitación específica.

En Uruguay, a nivel del gobierno central, no existe un sistema de Alta Dirección Pública, así como tampoco un sistema de cargos de libre designación similar a los DAS de Brasil. Tanto en la Administración central como descentralizada (exceptuando los Gobiernos Departamentales y Municipales), existen inmediatamente por debajo de Ministros y Viceministros los denominados "cargos de confianza", en su mayoría legalmente reconocidos.

Estos cargos, que en 1960 no superaban la treintena, en 2016 ascendían a 169 en el Poder Ejecutivo, y remiten a puestos de Directores de Direcciones Nacionales en Ministerios, que son ordenadores secundarios de gasto. Este número ha tenido una tendencia creciente progresiva, registrándose aumentos mayores en otras áreas del sector público. Por ejemplo, en el año 2016, se registraron además 64 cargos de confianza en Entes Autónomos y Descentralizados, y en toda la estructura del Estado el número ascendía a 850. No obstante, las designaciones directas (sin mediar concurso) en el Poder Ejecutivo constituyen un número mucho más significativo que los citados 169 cargos. A modo de ejemplo, en la administración descentralizada (excluyendo a las Empresas Públicas), que concentra la mitad del empleo público (alrededor de 150.000 funcionarios, en su mayoría en las áreas de Salud y Educación), un $5 \%$ de los más de 4.000 funcionarios ingresados en los últimos años lo hicieron por fuera del sistema de mérito. Por lo tanto, cerca de 200 funcionarios ingresaron discrecionalmente, y no se cuenta con información sobre en qué puestos de trabajo lo hicieron, aunque es razonable suponer que muchos se encuentran en cargos de alta responsabilidad. En consecuencia, se desconoce el número, los puestos que ocupan, las tareas que realizan y sus perfiles laborales, académicos y políticos.

En Uruguay no ha tenido lugar un debate público ni un tratamiento académico pormenorizado que promoviera un proceso de construcción de una Alta Dirección Pública, o la profesionalización de estos niveles de gobierno. La llegada de los 
gobiernos del Frente Amplio en 2005 no alteró el usual sistema de cuota políticopartidaria para ocupar los altos cargos de la maquinaria administrativa; en este caso repartidos entre las fracciones de este partido mayoritario. Durante la Presidencia de José Mujica (2010-2014) en particular, se retomó la histórica tradición consociativa del sistema de partidos uruguayo de coparticipación de los partidos de oposición en los Directorios de Entes Autónomos y Servicios Descentralizados.

El intento más comprehensivo de construir un cuerpo de funcionarios con características de Alta Dirección fueron los Ilamados "Cargos de Alta Conducción", que reemplazarían a los Directores de División pertenecientes a la carrera administrativa, quienes actúan por debajo de los cargos de confianza. La novedad de esta propuesta de mediados de la década de 1990 consistía en que estos funcionarios podían acceder a dichos cargos sin necesariamente provenir de las filas burocráticas, y estarían sujetos al cumplimiento de sus compromisos de gestión. En este sentido, la propuesta tenía rasgos propios del NPM. La implementación concreta de esta propuesta derivó en que 27 cargos fueron cubiertos en cuatro Ministerios piloto, constituyendo principalmente un cuerpo de apoyo al Director General de Secretaría (cargo de confianza que tiene a su cargo las tareas administrativas del Ministerio).

Sería erróneo equiparar este cuerpo de funcionarios a una Alta Dirección Pública en el sentido gerencial del término, ya que sus tareas remitían al apoyo al responsable político más que a la dirección con libertad de gestión. Se crearon cargos como los de Gerente de Planificación Estratégica, Recursos Humanos, Financiero Contable, Gestión del Cambio, entre otros; áreas de apoyo, no responsables por la provisión de bienes o servicios ni por la formulación de política pública. El sistema nunca tuvo un organismo único rector que regulara los mecanismos de reclutamiento, selección, evaluación y desvinculación del cargo, así como tampoco llegó a implementarse su evaluación a través de compromisos de gestión. A partir del año 2010, los cargos vacantes se fueron suprimiendo y el proceso quedó trunco. En el año 2013, con el nuevo Estatuto del Funcionario Público, se planteó extender la Alta Conducción (llamada Dirección Superior) a todos los Ministerios, como funciones (no cargos) ligadas a compromisos de gestión. Sin embargo, esta iniciativa nunca avanzó en la identificación concreta de dichas funciones ni sería a la postre implementada.

En definitiva, en la administración pública uruguaya, con excepción de algunas Empresas Públicas del dominio comercial industrial y financiero, no se ha podido avanzar en la constitución de un cuerpo de Directivos o Gerentes profesionales, como interfase entre la burocracia de nivel medio y los cargos políticos. Esta capa de funcionarios está ocupada por los cargos de confianza, que a diferencia de los DAS en Brasil, no están clasificados por niveles, ni existen disposiciones respecto a qué porcentaje de los mismos debe provenir de las filas del servicio de carrera. 
Al comparar ambos sistemas político administrativos, en lo que refiere a las interacciones entre cargos políticos y de carrera, surgen varios aspectos a destacar. El sistema de DAS en Brasil, presenta dificultades para la evaluación del rendimiento de estos funcionarios. Otro de los desafíos está en el plano de las remuneraciones con importantes variaciones y que no incentivan el ingreso de personal externo al servicio civil. Asociada a ello, se generan asimetrías en la composición de perfiles de ocupantes de cargos DAS de acuerdo a los órganos de que se trate. En otro plano, la ocupación de los cargos DAS no está ajeno a problemas de patronazgo, en parte derivados del clásico presidencialismo de coalición brasileño. Existe un complejo trade-off entre las negociaciones entre poderes para dar gobernabilidad y la posibilidad del Ejecutivo de imponer su agenda política, a través de la designación de DAS en los cargos más altos, por confianza presidencial. De esta forma, los DAS pueden también ser utilizados como una herramienta en una lógica de patronazgo partidario.

No obstante, el sistema de DAS ofrece un número importante de ventajas relativas al compararlo con el uruguayo. Por un lado, el sistema de cargos DAS penetra fuertemente la maquinaria administrativa, Ilegando a cargos medios. Esto permite a los Ministros, en caso de hacer un uso inteligente del instrumento, reclutar personal joven y preparado en un sistema de fast-track similar al que usan algunos países desarrollados. Esto en Uruguay no ocurre, ya que no están permitidas las entradas laterales a la carrera. En lo que respecta a la burocracia de más alto nivel del DAS (escalones 5 y 6), la designación de un $50 \%$ de funcionarios de carrera brinda garantías de profesionalización, al mismo tiempo que permite maximizar la responsiveness política con el restante $50 \%$ de designados, que pueden provenir del sector privado o de los partidos políticos. En cambio, en Uruguay, los cargos de confianza no tienen ningún requisito de perfil técnico ni requerimiento de provenir de filas de la administración pública. En ese sentido, la competencia técnica es sacrificada por los imperativos de lealtad política y el reparto partidarios. Si bien los cargos de confianza pueden presentar habilidades y competencias suficientes, no es posible señalar que sean las personas más aptas para ocuparlos.

\section{Reflexiones finales sobre los desafíos de los servicios civiles en Brasil y Uruguay}

Los déficits en la generación de servicios civiles fuertes y meritocráticos tienen consecuencias negativas para la consolidación de Estados que lideren el proceso de desarrollo de sus países. En ese sentido, las trayectorias de los servicios civiles en Brasil y Uruguay muestran luces y sombras. Brasil ha alcanzado un importante éxito en la reducción sustancial de fenómenos como el clientelismo y el patronazgo 
al nivel federal a partir de la selección meritocrática de funcionarios públicos; se redefinió el perfil de los servidores de un modo que favorece la incorporación de funcionarios altamente calificados; y la transparencia en el acceso a información se ha vuelto rutina en su Administración Pública. También en Uruguay los avances son notables. Se cuenta hoy con un servicio civil más grande, meritocrático, tecnificado, de carrera y rejuvenecido que en el pasado a partir de la inversión en sistemas de información y control al ingreso. No obstante, ambos países, adolecen de problemas de consolidación de un sistema de carrera unificado y en términos más generales, un "libreto" de reforma del servicio civil.

En Brasil, son múltiples las esferas en las que los intentos de reforma han sido escasos o inconducentes. La propia revalorización de los burócratas de carrera frente a los designados políticos en la alta esfera del gobierno no ha sido producto de una estrategia planeada y acordada. La ausencia de una estrategia actual consistente de reforma, y la falta de visión de conjunto ha favorecido una fragmentación y comportamientos egoístas ('my case is special') por parte de funcionarios, grupos corporativos y áreas del Estado. Más aun, el poder de ciertos funcionarios (fiscales, inspectores impositivos, oficialidad policial) se ha incrementado al punto de darles posibilidades para chantajear al Gobierno con sus demandas. Asociado a esa misma línea, los gobiernos no han sido capaces de gestionar efectivamente las carreras, que han impuesto su lógica de mercado en competencia, y cuyo management ha sido asimilado acríticamente al aumento salarial y de beneficios para los funcionarios. En términos de manejo de información, continúa pendiente un estudio pormenorizado de las plantillas de personal público por organización y agencia del Gobierno. Diversas transformaciones en áreas como la demografía, la tecnología, las técnicas modernas de gestión, la sociedad civil, las condiciones del mercado, entre otras, han estado ausentes del debate sobre reforma administrativa. Los efectos de este balance entre aciertos y fallos, se ven patentes en situaciones como que la "infra-burocratización" y la "sobre-burocratización" son patologías que coexisten en el Gobierno Federal y a la interna de los ministerios; en que las tradicionales distinciones entre administración directa e indirecta han tendido a diluirse; en la marcada fragilidad de la gestión humana dentro de los sistemas centras de la Administración Federal; en la acentuada dinámica de competencia entre carreras que actúan como facciones, desacopladas de su rol de Gobierno; y en la falta de coordinación entre stakeholders relevantes para trabajar en conjunto sobre estas problemáticas².

En Uruguay, la gestión del servicio civil adolece de serias limitaciones, asociadas a la persistente sobrerregulación e inadecuación entre funciones y competencias.

\footnotetext{
${ }^{2}$ Muchas de estas apreciaciones surgen de la presentación realizada en el marco del evento "Patronage in Transition. The Politics of Patronage in Latin America" por Gaetani y Luna (2018).
} 
En ese sentido, los avances han sido modestos, como lo demuestra la implantación parcial y posterior desarticulación de un nuevo sistema de carrera; la imposibilidad de formar una burocracia meritocrática de alto nivel basada en la gestión por resultados; y la desarticulación exhibida por los sistemas de evaluación de desempeño. La carrera en el sector público uruguayo no goza de prestigio o posibilidades de desarrollo profesional, para lo cual sería menester modificar la estructura de incentivos e innovar en las estrategias de captación, formación y evaluación de personal (RAMOS; MILANESI, 2016). El Estatuto de Funcionario Público aprobado en 2013 registra avances en materia de condiciones de trabajo, derechos, obligaciones, recategorización de vínculos laborales y nuevos componentes de flexibilidad laboral horizontal. No obstante, continúa anclado en una concepción corporativa y particularista de la función pública, dejando irresoluta la no correspondencia entre tipo de ocupación, posibilidades de carrera y remuneraciones, e impidiendo la posibilidad de carreras transversales y ascensos entre distintos organismos del Estado (RAMOS, 2013). Asimismo, han proliferado estrategias de by-pass a los marcos del derecho público, para gestionar en estructuras flexibles del derecho privado y se mantiene vigente la problemática del complejo vínculo entre partidos y burocracias, históricamente basado en patronazgo y clientelismo, y culpable de haber bloqueado el desarrollo de una burocracia autónoma de los partidos (RAMOs, 2003). En ese sentido, el uso de la maquinaria estatal como moneda de negociación inter e intra partidaria se ha efectivizado mediante el ingreso selectivo de personal de confianza partidaria en cargos de conducción con alta remuneración y estatus, mediante mecanismos informales paralelos a la carrera administrativa. Este fenómeno ha llevado a una primacía de la lógica política y la political responsiveness sobre la racionalidad técnico-burocrática en la gestión pública, habilitando a una participación muy limitada de la alta burocracia en el diseño de políticas y generando en consecuencia un déficit de capacidades netamente estatales.

En síntesis, el proceso de construcción de un servicio civil nacional requiere de estrategias consistentes y políticamente sostenibles. Buena parte de los procesos de reforma ha tornado los esfuerzos al respecto en dificultosos, esposmádicos y desbalanceados, dada la presencia de un excesivo número de decision-makers con poder de veto y escasas capacidades que lo vehiculicen. Todo ello afecta en última instancia las capacidades de una governance del sector público basada en criterios de desempeño y responsabilidad política como, motores de desarrollo de los respectivos países. 


\section{Referencias bibliográficas}

BANCo INTERAMERICANo de DeSARRollo (BID). Al servicio del ciudadano. Una década de reformas del servicio civil en América Latina (2004-13). BID. Washington DC. 2014. BAnco Interamericano de DeSARRollo (BID). Marco Analítico para el Diagnóstico Institucional de Sistemas de Servicio Civil. Diálogo Regional de Políticas. Barcelona. 2002. Cavalcante, P.; Carvalho, P. Profissionalização da burocracia federal brasileira (1995-2014): avanços e dilemas. Revista de Administração Pública, v. 51, n. 1, p. 1-26, 2015.

CAvalcante, P.; LotTA, G. Burocracia de médio escalão: perfil, trajetória e atuação. Brasilia: Enap, 2015.

CORTÁzAR, J. C.; FuenzalidA, J.; LAFUENTE, M. Sistemas de mérito para la selección de directivos públicos: ¿Mejor desempeño del Estado?: Un estudio exploratorio. BID. 2016. DIAS, R. As carreiras no serviço público federal brasileiro: breve retrospecto e perspectivas Brasil. Ipea, 2010.

Escola Nacional de AdMinistração Pública (Enap). Servidores públicos federais: novos olhares e perspectivas. Enap. Brasilia. 2015.

EVANS, P.; RAUCH, J. Bureaucracy and growth: a cross-national analysis of the effects of "weberian" State structures on economic growth. American Sociological Review, v. 64, n. 5, p. 748-765, 1999.

FILGUEIRA, F. et al. La economía política de la reforma del servicio civil en Uruguay: los años 90. BID. 2002.

GAETANI, F.; HEREDIA, B. La economía política de la reforma del servicio civil en Brasil: Los Años de Cardoso. BID. 2002.

GARcía, F. Cargos de confiança no presidencialismo de coalizão brasileiro. Brasilia: Ipea, 2005.

Graef, A.; Barbosa, M. d. P. A Organização de Carreiras do Poder Executivo da Administração Pública Federal Brasileira - O Papel das Carreiras Transversais.) A Política de Gestão de Pessoas na Administração Pública Brasileira: Eixos, Desafios, Resultados 2008.

GRINDLE, M. Constructing, deconstructing, and reconstructing career civil service systems in Latin America. John F. Kennedy School of Government, Harvard University. 2010.

GuINOVART, B. Diagnóstico institucional de sistema de servicio civil: el caso de Uruguay. BID. 2002.

Hood, C. Relationships between Ministers/Politicians and Public Servants. In: Peters, G.; SAvole, D. (Ed.). Governance in the Twenty-first Century. Montreal: McGill-Queen's University Press, 2000.

IACOVIELlo, M.; Rodríguez Gustá, A. Uruguay. In: (Ed.). Informe sobre la situación del servicio civil en América Latina. Washington DC: BID, 2006. (Diálogo Regional de Política. Red de Gestión y Transparencia de la Política Pública.).

ItURburu, M. Diagnóstico institucional del servicio civil en América Latina: Uruguay. 2014. 
LANZARO, J. La segunda transición en el Uruguay: gobierno y partidos en un tiempo de reformas. Montevideo, FCU, 1998.

LoNGO, F. La profesionalización del empleo público en América Latina. Estado de la cuestión. In: LoNGO, F.; RAMOS, C. (Ed.). La profesionalización del empleo público en América Latina. Barcelona: Fundación CIDOB, 2008.

Longo, F.; RAMió, C. La profesionalización del empleo público en América Latina. Barcelona.: Fundación CIDOB, 2008.

LLANO, M. Diagnóstico institucional del servicio civil en América Latina: Brasil. BID. 2014. NARBONDO, P.; RAMOS, C. La reforma de la administración central en el Uruguay y el paradigma de la nueva gerencia pública (1995-1999). Revista Uruguaya de Ciencia Política, v. 11, p. 35-58, 1999.

NUESCH, E. La política institucional de la reforma administrativa del Estado en Uruguay. Quinto Congreso Uruguayo de Ciencia Política ¿Qué ciencia política para qué democracia? Montevideo: AUCIP 2014.

OfiCina Nacional de SeRvicio CIVIL (ONSC). Vínculos laborales con el Estado 2016. ONSC. Montevideo. 2016.

PACHECO, R. Brasil: politización, corporativismo y profesionalización de la función pública. In: Longo, F.; RAMıó, C. (Ed.). La profesionalización del empleo público en América Latina. Barcelona: Fundacion CIDOB, 2008.

PHILIP, G. Democracy in Latin America. Surviving conflict and crisis? UK: Polity Publisher, 2003.

SeCretaria de Gestão Pública (Segep). Boletim Estatístico de Pessoal e Informações Organizacionais. Ministério do Planejamento, Desenvolvimento e Gestão. Brasilia. 2017.

RAMOS, C. La racionalidad de la administración pública en el contexto de la reforma del Estado. In: BODEMER, K. (Ed.). La Reforma del Estado. Más allá de la Privatización. Montevideo: FESUR-ICP, 1993.

La trayectoria del Estado uruguayo. Algunas virtudes, viejos vicios, nuevos ropajes y muchas incertidumbres. In: RAMOS, C. (Ed.). La reconstrucción gerencial del Estado. Enfoque políticos sobre la "Nueva Gestión Pública". Montevideo: ICPEBP, 2003.

El Nuevo Estatuto de Funcionario Público en Uruguay. In: ICP (Ed.). Política en Tiempos de Mujica (III). Informe de Coyuntura. Montevideo: ICP, 2013. p.257-270.

RAMOS, C.; MILANESI, A. ¿Un neoweberianismo imperfecto? Descifrando el modelo de gestión pública en el Uruguay durante los gobiernos del Frente Amplio In: CAO, H. e BLUTMAN, G. (Ed.). Estado y administración pública: paradojas en América Latina. Buenos Aires: Centro de Investigaciones en Administración Públicas - FCEUBA, 2016. cap. 10, p.241-279.

RAMOS, C.; SCROLLINI, F. Los nuevos acuerdos entre políticos y servidores públicos en la Alta Dirección Pública en Chile y Uruguay. Revista Uruguaya de Ciencia Política, v. 22, n. 1, p. 11-36, 2013. 
REINER, L. La reforma administrativa en Brasil: El proceso en la Cámara de Diputados. Congreso Internacional de la Asociación de Estudios Latino Americanos. Guadalajara 1997.

SANGUINETTI, M. N. La profesionalización de la función pública en Uruguay 2005-2013. Avances en la profesionalización del servicio civil en Uruguay. De la minimización a la resignificación de los servidores públicos. In: XVIII Congreso Internacional del Clad sobre la Reforma del Estado y de la Administración Pública. Montevideo: Clad 2013. SouzA, C. La nueva gramática política y burocrática del Gobierno Federal de Brasil. In: Blutman, G.; CAO, H. (Ed.). Estado y Administración Pública: Paradojas en América Latina. Buenos Aires.: UBA-FCE, 2016. 